\title{
PALEOFLORAS DA ANTÁRTICA E SUA RELAÇÃO COM OS EVENTOS TECTÔNICOS E PALEOCLIMÁTICOS NAS ALTAS LATITUDES DO SUL
}

\author{
TÂNIA LINDNER DUTRA
}

\begin{abstract}
ANTARCTIC PALEOFLORA AND THEIR RELATION WITH TECTONISM AND PALEOCLIMATEAT THE SOUTHERN HIGH LATITUDES. The Antarctic paleofloristic record and the new information about the paleontology of King George Island (South Shetland Islands) is discussed taking in to account its importance to paleogeographic reconstructions, stratigraphic correlations and palaeoclimatic inferences. The data confirm an East Antarctic paleofloristic assemblage dominated by gondwanic elements and preserved in intracratonic basins mainly during the Upper Paleozoic and Early Mesozoic. To West Antarctica, a Triassic (in the southern areas) and an Upper Jurassic to Neogene fossil floras shows a close relation with volcanic events and with the Australian and southern South America successions. In the latter areas, a Bennettitales and Cycadales dominated paleoflora characterise the beginning of Cretaceous and attests the arriving of modern conifers and first angiosperms. Until the end of this period will be marked by a vegetation compound mainly by Nothofagaceae- Podocarpaceae wood and Cyatheaceae-Dicksoniaceae ferns in the understorey that indicates a microthermic interval. During the Paleogene, a peak of diversity and the influx of thermophyllic angiosperms gives place to a "mixed flora", very similar to those growing in Southern South America and Australia-New Zealand. With the PostOligocene drifting-apart of South America and Antaretic Peninsula and the arriving of cold climates, those floras declined and nearly disappeared from the continent. The large amount of radiometric data associated with regionally distributed deposits allows to the proposition of a background to chronostratigraphy and correlations. On the other hand, give support to the suggestions of a diachronic dispersion to the Antarctic paleofloristic elements when compared with those from the other gondwanic continental areas, with precocity to those from Antarctic (Weddelian Province).
\end{abstract}

Keywords: Antarctica, Paleobotany, Stratigraphy, Paleogeography, Paleoclimate, Nothofagaceae.

Resumo O registro paleoflorístico da Antártica e novas informações obtidas para a ilha King George (South Shetland Islands) são aqui discutidas, sob a perspectiva de sua importância para a compreensão dos eventos paleogeográficos e paleoclimáticos e para as correlações. Os dados compilados para o setor oriental (Continente Antártico) e para as áreas ao sul da Terra de Graham, na Península Antártica, indicam o domínio de sucessões depositadas em bacias intracratônicas, com idades distribuídas entre o Permiano e o Triássico e uma íntima alinidade com as áreas gondwânicas. Já no conjunto de ilhas setentrionais da Península, as assembléias sugerem eventos posteriores ao final do Triássico, maior identidade com os depósitos da América do Sul e Austrália e a associação preferencial com processos vulcânicos, conseqüência da movimentação final das placas continentais. Em termos composicionais as tafofloras sugerem o predomínio de Bennettitales e Cycadales até o Cretáceo Inferior e, sua substituição por coníferas de tipos modernos e pelas primeiras angiospermas no final deste período, quando a paleoflora sugere a presença de bons teores de umidade e clima temperado. O Terciário, cujo início corresponde a um hiato deposicional, será marcado por um expressivo aumento de diversidade na vegetação. Aos elementos anteriores somam-se angiospermas termofílicas que, entre o final do Paleoceno e o Eoceno basal, comporão as "floras mistas ou de mescla", comuns às bacias do sul da América e Austrália-Nova Zelândia, mas com momentos diacrônicos de aparecimento em cada uma das áreas. O final do Eoceno marca um primeiro evento de extinção, seguido de outro mais drástico no limite Oligoceno - Mioceno, coincidente com o isolamento da Antártica e a formação da Corrente Circum-Antártica. O caráter tectônicamente perturbado de grande parte das litologias, que dificulta as correlações, especialmente nas ilhas setentrionais, é compensado pelo grande número de dados absolutos de idade e pela presença de depósitos capazes de serem acompanhados regionalmente. Este documentário, além de útil na ordenação dos eventos e das floras, confirma a Península Antártica (Província Weddeliana) como um importante centro de dispersão para muitos dos táxons que hoje caracterizam a vegetação austral.

Palcovras-Chave: Antártica, Paleobotânica, Estratigrafia, Paleogeografia, Paleoclima, Nothofagaceae

INTRODUÇÃO Formada a partir do fracionamento do Gondwana, a Antártica conservou uma posição polar desde o Mesozóico, enquanto as outras massas de terra austrais dela divergiram e originaram os modernos continentes do Hemisfério Sul. Sua atual cobertura pelo gelo sugere uma continuidade territorial e uma uniformidade de processos, que não corresponde a sua evolução geológica, bastante distinta quando comparada ao Continente Antártico (Antártica Oriental) e a Península (Fig. 1).

Esta história particular originou os diferentes depósitos e as paleofloras tratados a seguir. No tocante à porção norte do Arquipélago das Shetland do Sul e a ilha King George, os dados paleobotânicos referem-se aos obtidos durante as expedições do Pro- grama Antártico Brasileiro (PROANTAR).

\section{OREGISTRONOCONTINENTEANTÁRTICO(ANTÁRTICA} ORIENTAL) Paleozóico e Mesozóico Inferior O registro geológico do Continente reflete, mais que na Península, as antigas ligações gondwânicas, estendendo-se do Devoniano ao Jurássico, e com sucessões bastante completas relativas ao Permiano e Triássico (Taylor \& Taylor 1990, Bose et al. 1990, McLoughlin et al. 1997). A presença de estratos do Pré-Cambriano e do Paleozóico basal permanece duvidosa (Playford 1990).

As sessões provêm das montanhas Ellsworth, Príncipe Charles e, especialmente, das Transantárticas (Fig. 1). Aí, a base do Permianoé representada por folhelhos marinhos que, gradualmente, 


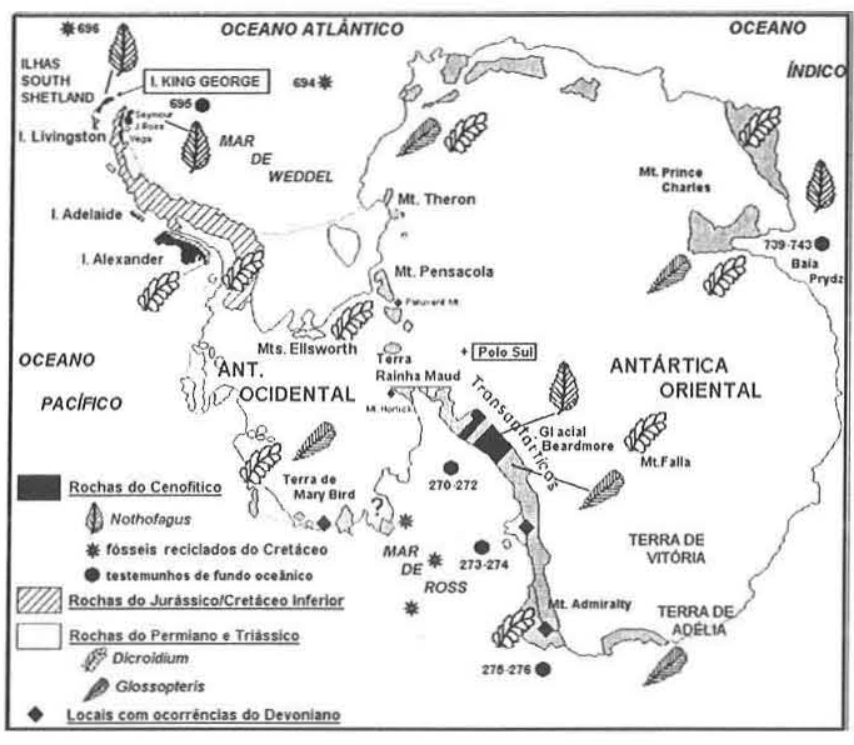

Figura 1 - As duas principais subdivisões da Antártica, idade dos depósitos e principais tipos de fósseis vegetais reconhecidos (mapa básico extraído de Bose et al. 1990).

dão lugar a condições mais rasas, cobertos por camadas de carvão com flora de Glossopteris. As impressões de folhas, preservadas em nódulos (coal-balls) e os lenhos autóctones associados, atestam uma vegetação que crescia, preferencialmente, em planícies aluviais e sob um clima quente e sazonal (Taylor et al. 1992).

Já o final do Permiano é melhor documentado no lado australiano do continente, permitindo acompanhar o declínio das pteridófitas e gimnospermas primitivas e a gradual extinção das glossopterídeas e cordaitales. A microflora permitiu a designação da Zona informal de Praecolpatites, caracterizada pela presença de P. sinuosus (Playford 1990), ausente nos níveis do Permiano Inferior (Zona Protohaploxymus) e do início do Triássico (Zona Alisporites).

O limite Permo-Triássico mostra a substituição dos depósitos de carvão por camadas vermelhas, indicando um diacronismo de resposta às mudanças climáticas, quando comparado aos continentes mais setentrionais do Gondwana.

A flora triássica, preservada nas Transantárticas e Terra de Vitória, evidencia o domínio inicial de licófitas e Peltaspermales, seguidas no Noriano, pelas Corystospermales, coníferas modernas e fetos (Taylor \& Taylor 1988, Millay \& Taylor 1990, Archangelsky 1996). Na base da Formação Fremouw (Triássico Inferior), logo acima dos últimos níveis com Flora Glossopteris, aparece uma variada fauna de répteis, correlacionável à da Zona de Lystrosaurus da África do Sul (Hammer 1990).

Cretáceo e Terciário Os depósitos concentram-se em 3 setores da Antártica, expostos por soerguimentos do final do Terciário: a) ao longo das Transantárticas, na Terra de Victória e no Estreito McMurdo; b) nas ilhas Kerguelen e em Prydz Bay e, c) na Península Antártica e Mar de Weddell (Fig. 1).

São conhecidos, ainda, em depósitos de plataforma, obtidos nos programas de sondagem de fundo oceânico (ODP, CIROS-1, MSSTS e DSDP), que registram três importantes quedas do nível do mar, ligadas a episódios glaciais, no limite Eoceno-Oligoceno (separação Austrália-Antártica), final do Mioceno Médio e Plioceno Inferior (Barker et al 1987). Na região do Mar de Ross, mostram que o gelo alcança o nível do mar no Mioceno (Murphy e Kennett 1985) e que bosques empobrecidos reaparecem no Plioceno (entre 2,5 e $5 \mathrm{Ma}$ ) a $80^{\circ} \mathrm{S}$ de latitude, com coníferas podocarpáceas, gramíneas e formas microfilas de Nothofagus, semelhantes a $N$. betuloides, que hoje cresce no sul da América e a $N$. gunni, da Tasmânia (Askin e Markgraf 1986). Segundo Truswell (1990), a área representou um refúgio entre as montanhas onde a teria sido mantida graças à umidade.

Para acompanhar o momento de abertura do Atlântico, as melhores sucessões provém dos testemunhos do Mar de Weddell (Fig. 2). Os depósitos mais antigos (entre 150 a $160 \mathrm{Ma}$ ) situam-se no flanco oriental da Península (del Valle et al. 1997, Riley et al. 1997) e se caracterizam por ambiente marinho inicial, com restrições e de anoxia, que dá lugar, pouco a pouco, entre o final do Jurássico e o Cretáceo Superior, a condições mais abertas, (Hathway 2000). Isótopos de oxigênio de conchas de foraminíferos mostram que o limite Paleoceno-Eoceno foi o período mais quente do Terciário (Robert \& Kennett 1994, furos 690 e 694, Fig. 1) e o início do Oligoceno, quando, dentre as argilas, as esmectitas e caulinitas são substituídas por ilitas, o de declínio mais acentuado na temperatura. A chegada do gelo ao nível do mar coincide aqui com o final do Plioceno (1,75 Ma), quando cessam os turbiditos (Barker et al. 1999).

Nothofagus, elemento importante das floras antárticas terciárias, ocorre nos testemunhos do Eoceno, compondo cerca de $60 \%$ das assembléias de palinomorfos (Truswell 1990).

Os dados de anomalias magnéticas das bacias oceânicas permitem estabelecer a cronologia dos eventos de separação das placas nas altas latitudes austrais. Para o sul do Atlântico e Índico ocidental, um primeiro pulso, ainda não suficiente para separar definitivamente Antártica e Austrália, coincide com a anomalia 34 de Tarling (1988), correspondente ao Jurássico- Cretáceo Inferior.

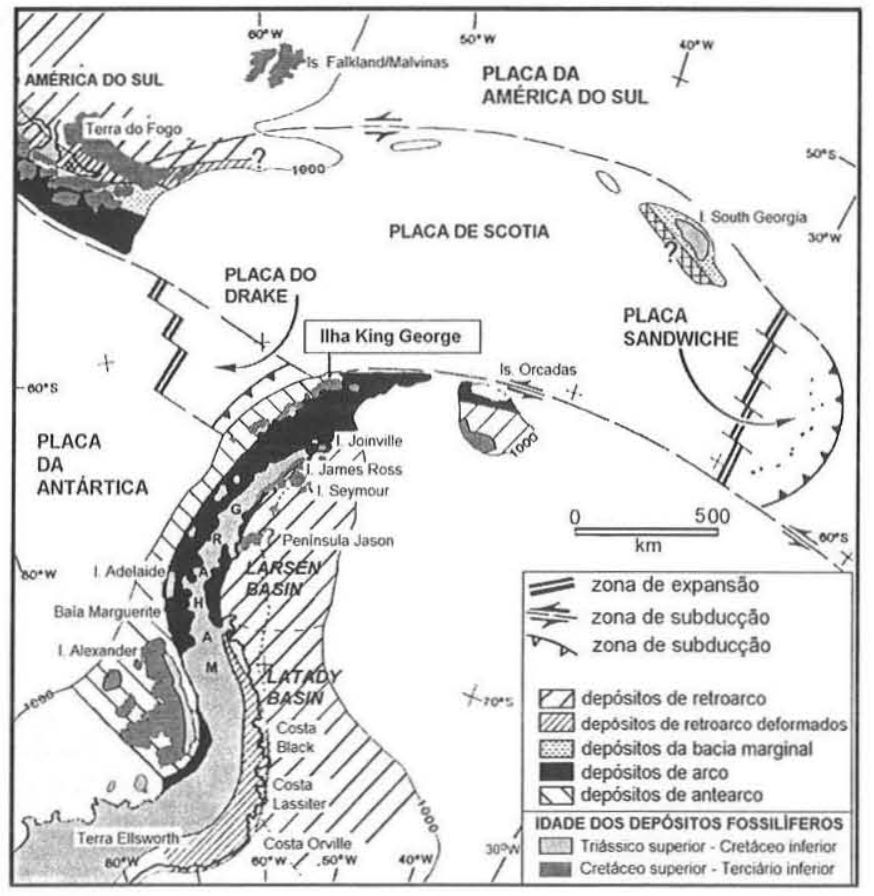

Figura 2 - Arcabouço tectônico da Península Antártica e do sul da América e as idades sugeridas para os depósitos (adaptado de Elliot 1988 e del Valle \& Rinaldi 1993 para a Bacia de Larsen). 
No Pacífico Sul e Tasmânia, inicia na anomalia 20 (Cretáceo Superior) e se prolonga até o Eoceno e, finalmente, no lado australiano do Índico, os eventos ocorrem no limite K -T (Lawver et al. 1991, Specht et al. 1992). Dados de Cunningham et al. (1995) sugerem que Antártica e América do Sul teriam permanecido próximas até pelo menos há $40 \mathrm{Ma}$, com gradual movimentação da Península no sentido horário em relação ao sul da América (entre 80 e 40Ma).

\section{OREGISTRONA PENÍNSULA (ANTÁRTICA OCIDENTAL)}

Para Elliot (1988) e del Valle e Rinaldi (1993), a conformação geológica atual da Península Antártica, resulta da complexa interação de um conjunto de pequenas placas e dos processos de subducção ocorridos desde o final do Paleozóico, em sua costa voltada para o Pacífico. Um magmatismo característico dos ambientes de arco e bacias de antearco associadas é testemunhado pelos espessos pacotes de rochas vulcânicas, sedimentares e plutônicas intrusivas, com idades entre o Triássico e o final do Terciário.

Junto às Shetland do Sul, o consumo do fundo oceânico foi inicialmente substituído por intensa atividade vulcânica (Cretáceo Superior), acompanhada de pulsos menores (66 Ma e $43 \mathrm{Ma}$ ), que levaram até o completo desaparecimento da microplaca Aluk.

Um panorama geral dos depósitos e do arcabouço estratigráfico a partir daí estabelecido, é apresentado a seguir.

Península Continental e os depósitos do arco Incluídas por Adie (1964) no Grupo Antarctic Peninsula Volcanic (APVG), as rochas metamórficas e vulcânicas do extremo norte e nordeste da Península continental (Graham Land) se interdigitam com conglomerados (leques aluviais) e depósitos de planícies de inundação, com restos vegetais, do Grupo Botany Bay (BBG). Estes depósitos são referência para o início da atividade vulcânica no final do Triássico, que se prolongou até o Cretáceo Superior (Farquharson 1984 e Fig. 3).

A idade dos numerosos fósseis de vegetais da Formação Mount Flora (em Hope Bay, BBG) sempre foi motivo de divergência (Smellie et al. 1984). Inicialmente atribuídos ao Jurássico Superior, por comparação com floras da Europa e da Índia (Nathorst 1907), a indefinição das idades no último continente e a falta de táxons diagnósticos não serviu de apoio a esta calibração. Alguns autores propuseram sua correspondência ao limite Juro-Cretáceo (Farquharson 1984), por comparação com as formas descritas na Argentina por Baldoni (1986). Para Gee (1989) e Rees (1993), no entanto, a presença de Goeppertella, cujos limites superiores na América do Sul situam-se no Jurássico Inferior, recua a idade para o Neotriássico, compatível com a idade Sm-Nd obtidos por Millar et al. (1990) e que tornam a paleoflora contemporânea a de Botany Bay, mais ao sul da Península (Morel et al. 1994),.

Dentre as 43 espécies de plantas identificadas, estão folhas grandes de Bennettitales (Ptilophyllum e Pterophyllum), Cycadales (Nilssonia), ramos de Araucariaceae (Elatocladus), Equisetales e pteridófitas (Gee 1989, Rees 1993). Apesar da nova cronologia proposta, o conjunto exibe grande semelhança com a flora neojurássica da Península Jason (Riley et al. 1997), associada a conchas de amonóides em níveis datados entre $160 \mathrm{Ma}-174 \mathrm{Ma}$ e $183 \mathrm{Ma}$ (del Valle et al. 1997) e com a do Cretáceo Inferior da Península Byers (Aptiano), na ilha Livingston, Shetland do Sul (Césari et al. 1999).

A Bacia de Larsen e os depósitos de retroarco (back-arc) A Bacia de Larsen (MacDonald et al. 1988 e del Valle et al. 1992), engloba a sub-bacia de James Ross (de Elliot 1988) e reúne espesso pacote de litotipos depositados, entre o Jurássico (Kimmeridgiano)

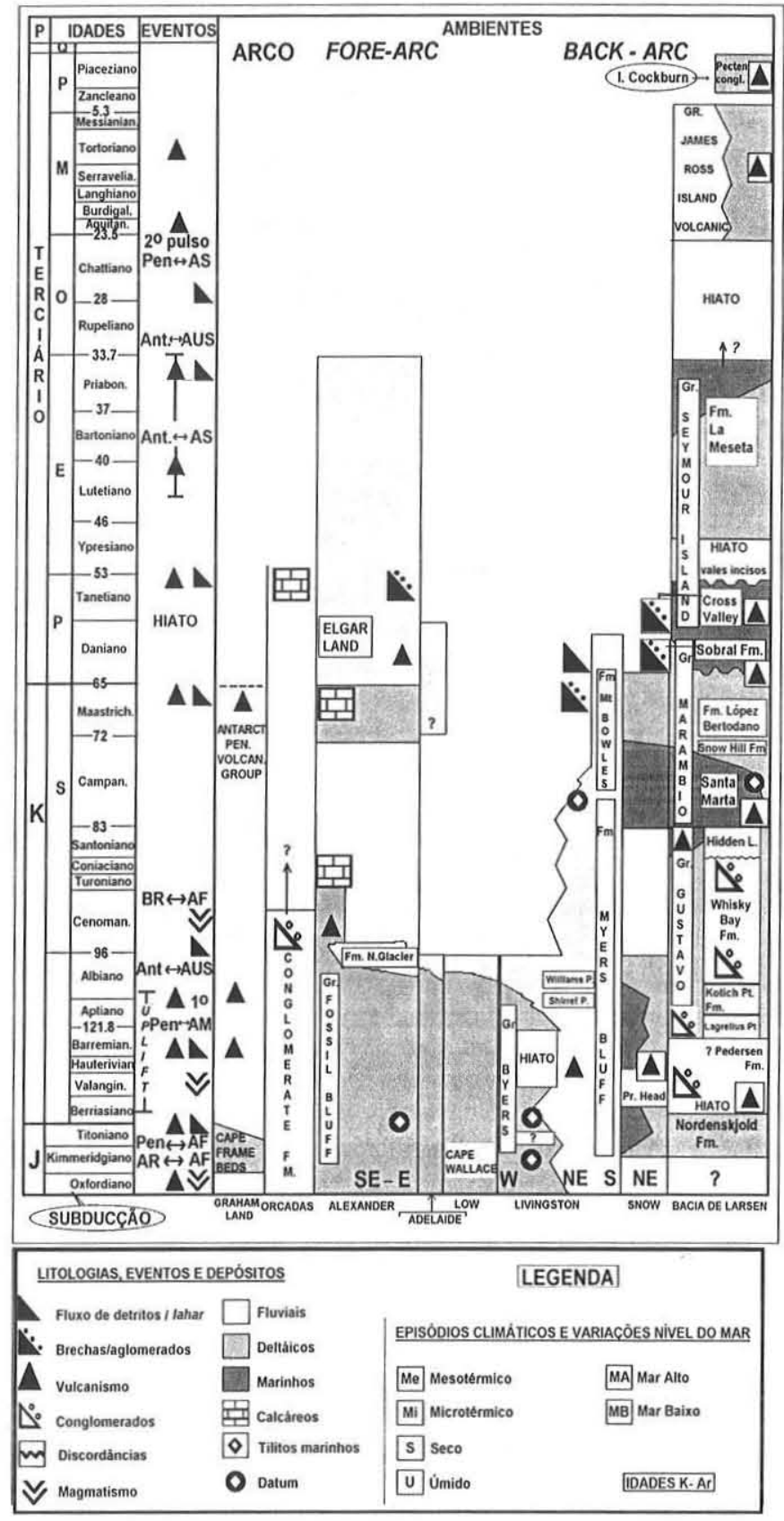

Figura 3 - Proposta de correlação e litoestratigrafia do setor norte da Península Antártica a partir do final do Jurássico. Os dados da Bacia de Larsen são de Hathway (2000). Para a Ilha King George ver Fig. 5.

e o Eoceno Superior (Figs. 2 e 3), sobre embasamento triássico (Hathway 2000).

Constitui a melhor sucessão de plataforma em latitudes tão altas do Hemisfério Sul e compartilha muitos aspectos com a Bacia Austral, na Patagônia (Olivero 1995). A presença de um megaciclo regressivo no final do Eocretáceo, período caracterizado por níveis globais de mar alto, sugere que a atividade ígnea e a tectônica, mais do que as variações eustáticas, controlaram sua deposição. Desde aí, e até o final do Oligoceno, formou uma bacia contínua no flanco oriental da Península, só perturbada pelos movimentos de abertura do Gondwana. 
Seu rico registro fossilífero testemunha o gradual desconfinamento do mar, entre o final do Jurássico e o Eocretáceo (Megaseqüência Transgressiva Pós-Rift de Hathway 2000), seguido de gradual queda do nível do mar, alternada com ciclos transgressivos menores, a partir do Cretáceo Superior. No início do Terciário, os ambientes marinhos rasos e costeiros dão lugar aos de caráter continental. O limite das megasequiências foi definido pelas mudanças na geometria da bacia (Macellari 1988, Pirrie et al. 1991).

Os fósseis mais antigos provêm da Formação Nordenskjöld ou Ameghino, uma deposição que sucede vulcanismo félsico e um hiato temporal que a separa do Grupo Botany Bay (Doyle \& Whitham 1991). O episódio transgressivo jurássico é atestado por restos de cefalópodes, bivalves e peixes (MacDonald et al. 1988), seguido da deposição de águas mais rasas e oxigenadas (Hathway 2000), onde se conservaram fragmentos de planta e material terrígeno, indicativos da proximidade de áreas emersas da Península.

Um novo hiato separa esta unidade dos conglomerados do Grupo Gustavo e da Formação Pedersen, de idade Aptiano basal, a partir de datação ${ }^{40} \mathrm{Ar}^{-39} \mathrm{Ar}$ (Hathway 2000). Entre os blocos foram encontrados restos de folhas, polens e icnofósseis que permitiram Aguirre-Urreta et al. (1990) interpretar os depósitos como representativos de leques submarinos, interdigitados a um sistema de slope apron. Incursões de areias no topo indicam as fácies de leques deltáicos e o raseamento da bacia e, rochas vulcanoclásticas retrabalhadas, um intervalo de quiescência no magmatismo do arco.

Sem discordância visível seguem-se os grupos Marambio (Pirrie et al. 1991) e Scymour, distribuídos entre o final do Cretáceo e o início do Eoceno (Fig. 3). Representam uma sucessão marinha rasa e deltáica caracterizada por uma série de ciclos regressivos e transgressivos que preencheu a bacia a partir de sedimentos siliciclásticos derivados das áreas continentais da Península. A Formação Santa Marta (Olivero et al. 1986, Crame et al. 1991), contém uma mistura de organismos marinhos e continentais (dentes de tubarão, dinossauros ornitísquios, mosassaurídeos, Plesiosauria, restos de moluscos amonóides e grãos de pólen) que contribuíram para limitar a ocorrência ao SantonianoCampaniano e sugerir a manutenção da proximidade entre América e Antártica (Richter \& Ward 1990, Olivero et al. 1991). O limite Campaniano-Maastrichtiano, caracterizado mundialmente por nível de mar alto é aqui, mais uma vez, caracterizado pela migração do onlap costeiro para leste (Macellari 1988).

A Formação López de Bertodano tem idade variável entre o Campaniano e o Terciário basal (Palamarczuk et al. 1984). A riqueza em fósseis marinhos e continentais (Crame 1992) e a pouca perturbação das camadas permitiu a Macellari (1984 apud Sadler 1988) subdividi-la em dez intervalos, com características deposicionais distintas, em contexto transicional.

As unidades seguintes documentam o limite K-T e os eventos erosivos do Paleoceno.

O topo do Maastrichtiano é o momento de inundação máxima da bacia. Dá lugar a depósitos deltáicos de plataforma externa acima do nível de ação das ondas de tempestade. O conjunto, incluído na Formação Sobral (Pirrie et al. 1991), preenche canais escavados na plataforma durante um evento erosivo do início do Paleoceno (Sadler 1988). A idade, e condições de umidade do paleoclima, foram inferidas a partir da variedade de restos de planta, com coníferas podocarpáceas e angiospermas (Cunoniaceae e Elaeocarpaceae) comuns à moderna flora da Austrália e Nova Zelândia (Wrenn e Hart 1988) e de Valdívia, no Chile.

Já no Eoceno, a paleoflora mostra um panorama distinto.
Truswell (1990) considerou os palinomorfos como um mosaico da vegetação do Terciário Inferior da Austrália. Este termo assemelha-se à flora mista de Specht et al. (1992) deste mesmo continente e intervalo de tempo e ao utilizado por Pole (1994), para a paleoflora da Nova Zelândia. Na Argentina, Romero (1978) chamou-a de flora de mescla. Para os pesquisadores, a convivência de elementos, hoje distribuídos em diferentes biomas e latitudes, reflete a chegada do calor e um incentivo a maior diversidade, provocado pelo surgimento de áreas elevadas, encostas e regiões costeiras, em resposta à separação dos continentes.

As suas rochas foram incluídas na Aloformação La Meseta (Marenssi et al. 1998) e representam um ciclo sedimentar granocrescente completo, o qual denuncia a retomada de condições marinhas rasas, sob influência de marés, com influxos cíclicos de sedimentitos fluviais. Um hiato diacrônico caracteriza a base e a sedimentação preenche vales incisos no topo da Formação Cross Valley (Fig. 3). A paleoflora, estudada por Gandolfo et al. (1998), se assemelha muito às que veremos para as sucessões da ilha King George (Formação Fossil Hill e as "Dragon Glacier Plant Beds"), com folhas grandes e de margens inteiras (32\%), associadas a camadas calcificadas, com pequenos nódulos e feições em tablete ("barra de chocolate" de Case et al., 1988). Pegadas de aves não voadoras (ratitas), acompanhadas de restos de tartarugas, caranguejos, mamíferos ungulados e palinomorfos (no Telm 7 de Tambussi et al. 1994 ou Alomembro Submeseta de Marenssi et al. 1998) são igualmente interessantes para as correlações. Na ilha King George, estes icnitos caracterizam o topo da sucessão em Fossil Hill (Li Jianjun \& Zhen Shuonan 1994), embora aí constituam a única evidência da presença de vertebrados.

A estrutura das comunidades vegetais manter-se-a até o nível mais jovem da Formação La Meseta, momento em que aparecem os primeiros sinais de isolamento das faunas, sugerindo a formação de barreiras geográficas e/ou gradientes latitudinais (Reguero et al. 1998). As folhas de Nothofagus tornam-se pequenas e o gênero é quase exclusivo nestes níveis, indicando a chegada do frio (Case 1988, Zamaloa et al. 1987). O hiato deposicional que marca o início do Oligoceno na bacia corrobora esta hipótese (Fig. 3). É seguido por vulcanismo intenso no Terciário Superior, ligado à tectônica do Arco de Scotia. No limite Plioceno- Pleistoceno uma nova elevação do nível do mar, origina a sucessão progradante que, segundo Gazdizicka \& Gazdzicki (1994), originou os conglomerados a Pecten da ilha Cockburn e os sedimentos rudáceos com Chlamys anderssoni, com idades entre $3.95 \mathrm{Ma}$ e 2.8 Ma.

A deposição na sub-bacia de James Ross é importante por permitir acompanhar o caráter endêmico e a heterocronicidade de migração das floras da Península a partir do final do Campaniano (Askin 1989, Askin et al. 1991). Baseado nas assembléias de dinoflagelados e organismos marinhos, Crame (1992) sugere que este momento é o do primeiro aparecimento de Nothofagus no norte da Península. Já no Maastrichtiano comporá cerca de $40 \%$ das assembléias (Dettmann \& Jarzen 1990, Truswell 1990, Dutra \& Batten 2000) e, a partir daí, utilizando as áreas emersas da Província Weddelliana (Case 1988), irá dispersar para as outras regiões austrais da América e Austrália.

As ilhas ocidentais e os depósitos de antearco Em que pese seu contexto geológico distinto, as ilhas ocidentais da Península registram processos semelhantes aos acima descritos, com rochas distribuídas a partir do Permo-Triássico que mostram a passagem durante o Cenofítico, de ambientes marinhos para continentais (Figs. 1, 3 e 4). O conjunto chama a atenção, contudo, por não 
conter restos de animais terrestres, excetuadas as já aludidas pegadas de aves, sugerindo que seu caráter insular deve ter se estabelecido desde muito cedo (Dutra \& Batten 2000).

Alexander $\left(70^{\circ} \mathrm{S}-73^{\circ} \mathrm{S}\right)$ contém uma paleoflora importante por calibrar a chegada das angiospermas às altas latitudes, entre as quais formas ancestrais de Nothofagaceae, durante o Albiano Superior (Cantrill \& Nichols 1996).

$\mathrm{Na}$ ilha Adelaide $\left(65^{\circ} \mathrm{S}\right)$ macrofilos de angiospermas, com venação craspedódroma (Nothofagus?), e polens tricolpados e colpados permitiram reavaliar a idade jurássica inicial. Corpos plutônicos intrusivos forneceram idades entre $60 \pm 2$ e $63 \pm 3 \mathrm{Ma}$ (Pankhurst 1982).

Arquipélago das Shetland doSul(Figs. 3e 4a) Oregistro fossilífero nas pequenas ilhas mais ao sul é pouco significativo, em parte por ser pouco conhecido, em parte pelo domínio de rochas metamórficas e vulcânicas. Esta é a situação em Low, Smith e Deception, distribuídas em torno dos $63^{\circ} \mathrm{S}$.

Na ilha Snow $\left(62^{\circ} \mathrm{S}-61^{\circ} \mathrm{W}\right)$, os únicos fósseis são restos de vegetais compostos por compressões de frondes de coníferas e fetos, sem angiospermas, similares às vistas para Hope Bay (Torres et al. 1995). A identificação de Ptylophyllum antarcticum e as assembléias de palinomorfos, permitiram datá-los como do JuroCretáceo (Askin 1983, Phillipe et al. 1995).

A ilha Livingston $\left(62^{\circ} 30^{\prime} \mathrm{S}\right)$ reúne a maior representação temporal e número de estudos. O embasamento neopaleozóico é coberto por turbiditos do Triássico (Grupo Trinity Península), também correlacionáveis aos da Península Continental (Kelm \& Hervé 1994) e as rochas mesozóicas se parecem com as de Alexander, com restos de lenho, folhas e polens (Duane 1994). A paleoflora da Formação Cerro Negro (Grupo Byers Península), caracterizada pela presença de cf. Pseudoctenis ensiformis (Césari et al. 1999), foi recentemente atribuída ao Aptiano Inferior, a partir de dados idades absolutas (120 a $119 \mathrm{Ma}$ ) e conteúdo polínico. A presença de Cyatheacidites annulatus sugere um clima frio e úmido e ambientes sujeitos à perturbação (Truswell 1990).

Finalmente, as ilhas Robert e Nelson (Fig. 4a), dominadas por processos vulcânicos e metamórficos, seguem praticamente desconhecidas. Na última, apenas o Pontal Rip (NE) mostrou tufos favoráveis à presença de fósseis. Numa sucessão de cerca de 3 metros de espessura, aparecem restos de lenhos carbonizados e impressões de folhas, onde Nothofagus, angiospermas primitivas e pteridófitas, sugerem uma idade Cretáceo Superior, por correlação com níveis semelhantes no sul da ilha King George (Dutra et al. 1996).

Ilha King George (Figs. 4be 5) Contém uma sucessão cenofítica exclusiva em expressão e pela quantidade de restos vegetais identificados. O arcabouço estratigráfico da sucessão, eminentemente vulcanoclástica, foi proposto inicialmente por Birkenmajer (1980 e 1988) e Smellie et al. (1984), baseados nos trabalhos pioneiros dos ingleses, e incluía "Vulcânicas jurássicas" na base e uma "Suite Intrusiva Andina”, de idade Mioceno-Plioceno, no topo. Outra suite intrusiva de idade Paleoceno Superior, havia sido sugerida por Adie (1964) e Barton (1965).

Trabalhando na Baía do Almirantado e áreas ao norte, Birkenmajer (1980) incluiu a sucessão no Supergrupo King George Island, com 5 grupos, e propôs um sistema estrutural de blocos, formado no final do Cenozóico, devido ao rearranjo de placas como consequiencia da abertura do Mar de Drake, que teria

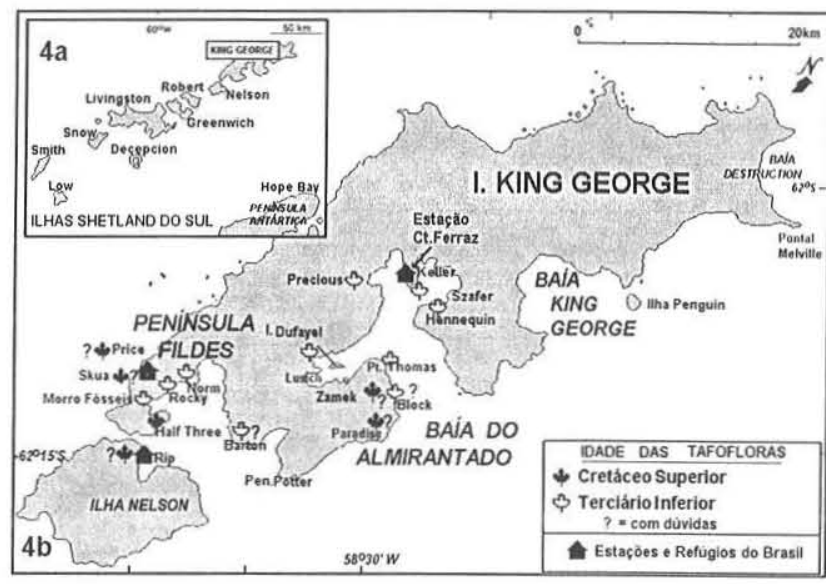

Figura 4-4a-Arquipélago das Shetland do Sul. 4b-Principais localidades fossilíferas e a idade da deposição na Ilha King George, segundo Dutra (1997a).

remobilizado as litologias. Trabalhando somente na Península Fildes, pesquisadores chineses liderados por Shen Yanbin (1994), propuseram um arcabouço estratigráfico distinto (Fig. 5).

Os restos de vegetais são amplamente distribuídos. Coletados inicialmente de modo esparso (Orlando 1964, Troncoso 1986), foram sistematizados, embora ainda em caráter localizado, por Czajkowski \& Rösler (1986)e Torres (1990), na Península Fildes e, por Birkenmajer \& Zastawniak (1986), Birkenmajer \& Zastawniak (1989a, 1989b) e Zastawniak (1981), na Baía do Almirantado. A utilização de métodos de datação absoluta forneceu idades mais antigas em torno de 71 e $77 \mathrm{Ma}$, respectivamente para cada um dos locais (Birkenmajer et al. 1986, Wang \& Shen Yanbin, 1994), servindo para eliminar a possibilidade da presença de litologias do Jurássico.

As pesquisas brasileiras (PROANTAR) propiciaram a coleta sistemática nos dois principais locais da ilha e uma proposta mais abrangente de ordenação das floras (Dutra \& Batten 2000, Dutra 2001), que levou em conta sua relação com o documentário nas outras áreas da Península, mudanças de fisionomia das folhas nas assembléias, calibração dos eventos paleoflorísticos com os processos geológicos de caráter mais regional e as idades radiométricas disponíveis (Fig. 5).

Esta abordagem permitiu a identificação de fósseis in situ de idade Campaniano Superior na Baía do Almirantado, previamente supostos a partir de material rolado em blocos de morena (Zastawniak 1994), e à semelhança dos que haviam sido encontrados por Cao Liu (1994), na Península Fildes. Além disso, novas tafofloras com esta idade foram encontradas (Dutra et al. 1996, Dutra \& Batten 2000).

Nothofagus está presente ao longo de toda a seqüência, tanto na micro como na macroflora. O Cretáceo se caracteriza pela presença de formas primitivas do gênero, com polens dos grupos fusca e brassii modernos, tais como, Nothofagidites senectus (grupo ancestral a), Nothofagidites cf. $N$. emarcidus, $N$. endurus, Nothofagidites cf. $N$. brachyspinulosus e Nothofagidites cf. N.rocaensis (Zhou Zhiyan \& Li Haomin 1994). Entre as folhas, tipos exclusivos e também com caracteres primitivos (Nothofagus cretaceae Zastawniak 1994 e N. zastawniakae Dutra 2000b), são acompanhados de angiospermas (Fig. 6), coníferas podocarpáceas e pteridófitas das famílias Cyatheaceae e Dicksoniaceae. A pre- 


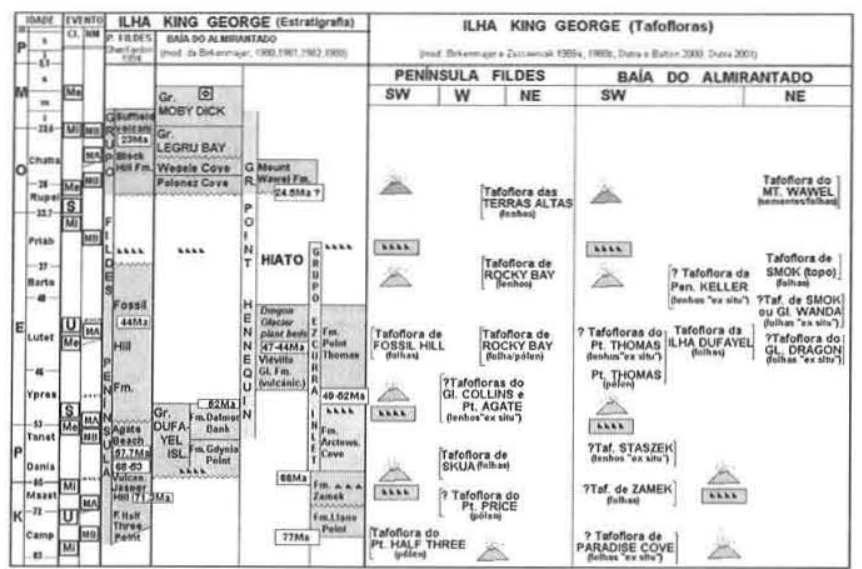

Figura 5 - Proposta de ordenação das tafofloras na ilha King George (Dutra 2001) e a calibraçäo com os eventos na subbacia de James Ross. Idades radiométricas de Birkenmajer et al. (1986). Soliani Jr: et al. (1988) e Wang \& Shen Yanbin (1994). Eventos de magmatismo, entre 145.6 e $97 \mathrm{Ma}$, segundo Johnson (1997) e unidades cronoestratigráficas e geocronológicas do ISC-IUGS, UNESCO.

sença de níveis de carvão sugere um clima temperado úmido.

As tafofloras seguintes permitiram acompanhar a evolução e a resposta da vegetação às modificações climáticas ocorridas durante o Terciário. $\mathrm{O}$ aumento do tamanho das folhas sugere iniciais temperaturas mais amenas (Paleoceno Superior-Eoceno Médio, Figs. 7 e 8) e, sua redução gradual, o ingresso de climas frios (Eoceno final e Oligoceno, Fig. 9). No Eoceno, Nothofagus betulifolia Dutra 2000b e N. hilleri Dutra 2000b, apresentam folhas com cerca de $10 \mathrm{~cm}$ de comprimento. Os representantes do gênero eram importante componente das florestas de angiospermas (Fig. 8) e coníferas. Os elementos do substrato são variáveis nos diferentes locais, mas a presença de gramíneas em troca das pteridólitas é típica deste intervalo. Associados a Gunneraceae e Araucariaceae (exclusivas deste momento), indicam calor e proximidade com o mar.

A paleoflora mostra uma grande alinidade com a das bacias austrais da América do Sul, especialmente com as da Patagônia (Berry 1928, Berry 1938, Frenguelli 1941). Para Nothofagus apóiam um centro de dispersão, e provável origem, em áreas do norte da Península no Campaniano e, sua posterior migração para os outros continentes do Hemisfério Sul. como proposto por Dettmann e' al. (199()) e Askin (1990). No Gondwana Oriental, a afinidade é mais expressiva com a Nova Zelândia (Pole 1992, Pole 1994), especialmente no Terciário Inferior.

Os episódios de frio sugeridos por Birkenmajer e Zastawniak (i989a, 1989b) e Birkenmajer et al. (1986), não parecem ser a única explicação para a substituição temporal e a extinção de determinados grupos, excetuado, provavelmente, o do limite EocenoOligoceno. Apesar de poderem ter condicionado as mudanças morfológicas e de fisionomia das folhas, o vulcanismo restrito em 53-57 Ma, 40 Ma e $23 \mathrm{Ma}$, parece ter sido o fator que produziu os efeitos mais profundos sobre a capacidade da vegetação de recolonizar os ambientes e na preservação dos restos (Pereira $e t$ al. 2()()3). O último deles, somado à queda da temperatura e o isolamento geográfico em relação à Américia, acabou por causăr sua dizimação.
CONSIDERAÇÕES FINAIS Do exposto, ressalta-se o importante papel das floras da Antártica para o conhecimento dos processos evolutivos, paleogeográficos e paleoclimáticos das altas latitudes do sul e sua relação com os ocorridos em outras regiões do Gondwana.

O continente Antártico (Antártica Oriental) guarda principal-

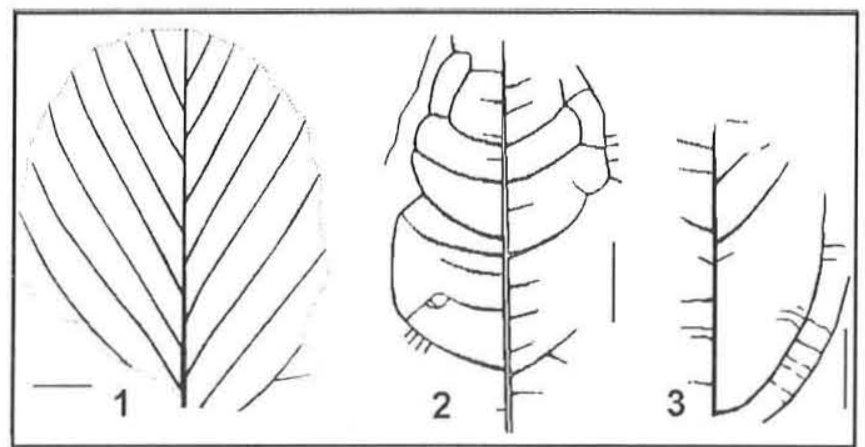

Figura 6 - Tipos morfológicos de angiospermas do Campaniano Superior da illa King George (Formação Half Three Point/Formação Zamek). 6.I - morfotipo protofilico (N. zastawniakae Dutra 2000b); 6.2 - morfotipo laurofico (aff. Ficophyllum sp.); 6.3 morfotipo laurofílico (Laurelia sp.). Dados de Dutra (1989, 1997b, 2001). Escala $=1 \mathrm{~cm}$.

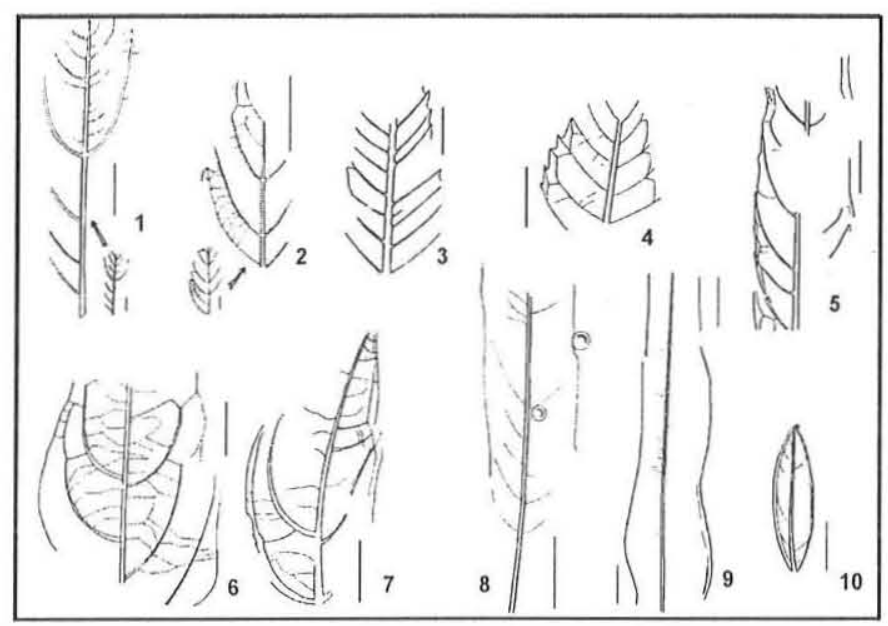

Figura 7 - Morfotipos de angiospermas do Paleoceno Superior? - Eoceno Inferior da Ilha King George (Formação Dalmor Bank), segundo Dutra (2001). 7.1 - morfotipo laurofílico, afim com Nectandra chilena Berry 1922 e Nectandrophyllum Engelhardt, do Paleoceno- Eoceno do Chile; 7.2 - morfotipo celastrofilico (Elaeocarpaceae?); 7.3 - morfotipo sapindofilico/ cunoniofilico (Sapindaceae/Cunoniaceae?), com afinidade com Paulinia sp., Cupania latifolioides e Thouinia sp., do Terciário do Chile (Berry 1922) ; 7.4 - morfotipo celastrofílico (Elaeocarpus sp.?); 7.5 - morfotipo celastrofílico (Monimiaceae), afim a Laurelia sp.; 7.6 - Dicotilophyllum sp. 8 (Li Haomin, 1994), Anacardiaceae; 7.7 - morfotipo laurofilico (Rhamnaceae?); 7.8 e 7.9 - morfotipos mirtofilicos (Myrtaceae, sect. Leptospermoidea); aff. Eucalyptus sp.; 7.10 - morfotipo mirtofilico (Myrtaceae, sect. Mirtoidea).. aff. Myrciaria sp. Esca$l a=l \mathrm{~cm}$. 


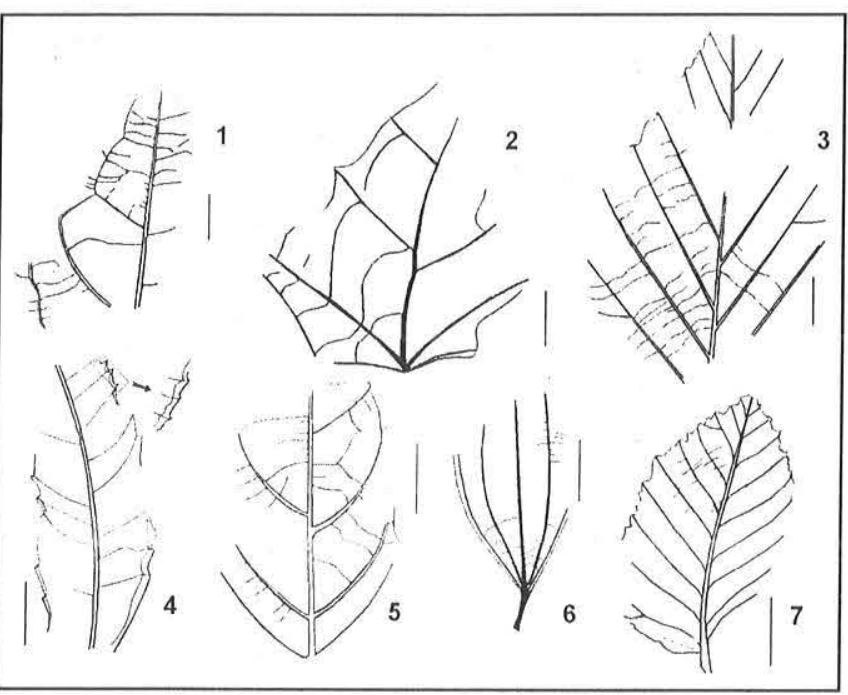

Figura 8-Morfotipos de angiospermas do Eoceno Médio, ilha King George (Formações Fossil Hill/Point Thomas e "Dragon Glacier Plant Beds"). segundo Dutra (2001). 8.1 Sterculiaephyllum latitrilobatum Zastawniak; 8.2- Sterculia cf. washburnii Czajkowski e Rösler; 8.3 -Nothofagus sp. aff. N. alessandri Espinosa; 8.4-forma indeterminada afim com Sapindaceae e Aquifoliaceae, similar a Banksia antarctica de Torres (1990) e Dicotylophyllum sp. 6 de Li Haomin (1994); 8.5 - morfotipo laurofílico de Birkenmajer e Zastawniak (1986), associada a Citronella sp. (Troncoso 1986) e Dicotylophyllum sp. 10 (Li Haomin 1994); 8.6-morfotipo acrodrômico, associado a Smilacaceae (Smilax duseni) por Torres (1990) e a Melastomataceae (Pentaneurum duseni) por Li Haomin (1994); 8.7 - Nothofagus subferruginea (Dusén) Tanai. Escala $=1 \mathrm{~cm}$.

mente rochas do Paleozóico e Mesozóico, com grande afinidade com outros setores do Gondwana. Bem documentado na obra de Taylor e Taylor (1990), seu registro é aqui atualizado.

A Península Antártica (Antártica Ocidental), por outro lado, com sucessões distribuídas desde o Triássico até o final do Terciário, permite a calibração dos momentos de separação e seu efeito sobre o clima e a vida nas altas latitudes. A possibilidade de avaliar o balanço entre os processos autocíclicos e alocíclicos tem

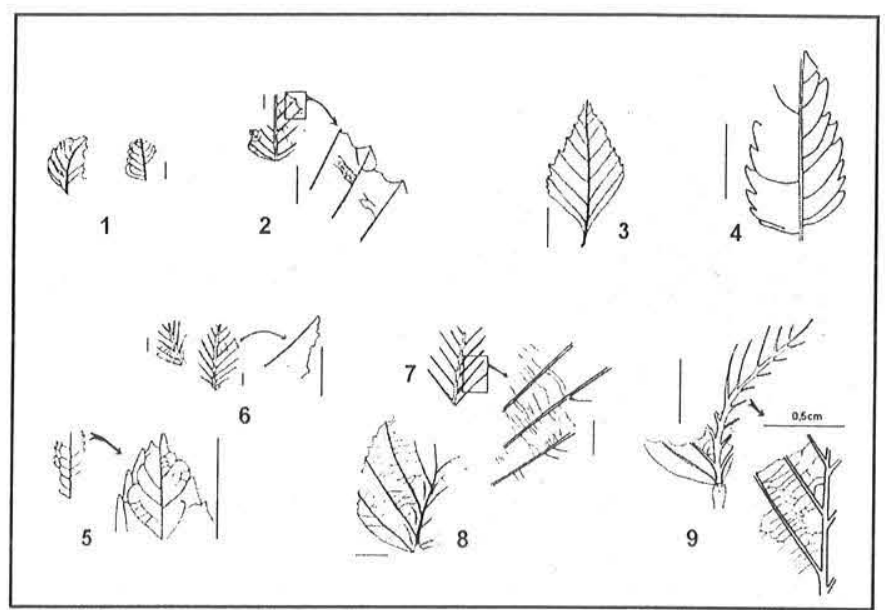

Figura 9 - Morfotipos de angiospermas no Eoceno Superior ? Oligoceno Inferior da Ilha King George (Formação Mount Wawel), segundo Dutra (2001). 9.1 -Berberidaceae: cf. Berberis laurifolia Berry 1937; 9.2 - Rosaceae: Rubus primaverae Frenguelli, 1941; 9.3 - folhas microfilicas de características perenes, afins com tipos modernos de Nothofagus subgênero Nothofagus, tais como N. betuloides (Mirb.) Oersted. e N. cunninghamii (Hook.f.) Oersted; 9.4 - Cupania grosse-serrata (Engl.) Berry 1938 (Sapindaceae/Cunoniaceae); 5 Roophyllum sp. (Anacardiaceae); 9.6, 9.7, 9.8 e 9.9 - folhas microfílicas de vernação plicada, sugerindo deciduidade e similares as de N. antarctica (Forst.) Oersted, forma moderna da Patagônia. Escalas $=1 \mathrm{~cm}$.

aí, portanto, um de seus melhores laboratórios.

Agradecimentos Ao Programa Antártico Brasileiro (PROANTAR), Comissão Interministerial para os Recursos do Mar (CIRM) e Conselho Nacional de Desenvolvimento Técnico e Científico $(\mathrm{CNPq})$, pelo apoio às campanhas de campo. Aos colegas, Dr. Enio Soliani Jr., Dr. Ubiratan Ferruccio Faccini, Dra. Rosemary Rohn, Dra. Zara Lindenmayer, Dra. Margot GuerraSommer e Dr. Oscar Rösler, pelas discussões sobre os dados geológicos e paleobotânicos. Aos revisores da RBG pelas sugestões ao manuscrito.

\section{Referências}

Adie R. J. 1964. Stratigraphic correlation in West Antarctica. In: R.J. Adie (ed.) Antarctic Geology, Proceedings of the First International Symposium on Antarctic Geology. pp.307-313.

Aguirre-Urreta M.B.. Buatois L.A., Chernoglasov G.Ch.B., Medina F.A. 1990). First Polychelidae (Crustacea, Palinura) from the Jurassic of Antarcticat. Antartic Science, 2:157-162.

Archangelsky S. 1996. Aspects of Gondwana paleobotany: gymnosperms of the Paleozoic-Mesozoic transition. Review of Paleobotany and Palynology, 90: 287-302.

Askin R. A. 1983. Tithonian (Uppermost Jurassic) - Barremian (Lower Cretaceous) spores, pollen and microplankton from the South Shetland Islands, Antarctica. In: R.L. Oliver, P.R. James, J.B. Jago (eds.)
Antarctic Earth Sciences, pp. 295-297.

Askin R. A. 1989. Endemism and heterochroneity in the Late Cretaceous (Campanian) to Paleocene palynofloras of Seymour Island, Antarctica: implications for origins, dispersal and paleoclimates of southern floras. In: J.A. Crame (ed.) Origins and Evolution of the Antarctic Biota, Geological Society Special Publication, 47:1(07-119.

Askin R.A. \& Markgraf V. 1986. Palynomorphs from the Sirius Formation, Dominium Range, Antarctica.

Askin R.A., Elliot D.H., Stilwell J.D., Zinsmeister W.J. 1991. Stratigraphy and paleontology of Campanian and Eocene sediments, Cockburn Island, Antarctic Peninsula. J. South Am. Earth_Sciences, 4: 99-1 17.

Baldoni A.M. 1986. Caracteristicas generales de la megaflora, especialmente 
de la especie Ptilophyllum antarcticum, en el Jurásico SuperiorCretácico Inferior de la Antartida y Patagonia, Argentina. Bol. Instituto de Geociências, USP, Série Científica, 17:77-87.

Barker P.F. and the Leg 113 shipboard scientific party, 1987. Glacial History of Antarctica. Nature, 328: 115-116.

Barker P.F., Barrett P.J., Cooper A.K., Huybrechts P. 1999. Antarctic glacial history from numerical models and continental margin sediments. Palaeogeog. Palaeoclim. Palaeoeco., 150:247-267.

Barton C. M. 1965. The Geology of South Shetland Islands. III. The stratigraphy of King George Island. Scientific Reports of the British Antarctic Survey, 44: 1-33.

Berry E. W. 1922. The flora of Concepción- Arauco coal measures of Chile. Johns Hopk. Univ. Stud. Geol., 4:73-142.

Berry E.W. 1928. Tertiary fossil plants from the Argentine Republic. Proceedings of the United States Natural Museum, 73(22):1-27.

Berry E. W. 1938. Tertiary flora from the Rio Pichileufú, Argentina. GSA Special Papers, 12:1-140.

Birkenmajer K. 1980. Tertiary volcanic-sedimentary succession at Admiralty Bay, King George Island (South Shetland Islands, Antarctica). Studia Geologica Polonica, 64: 7-65.

Birkenmajer K. 1988. Tertiary glacial and interglacial deposits (South Shetland Islands, Antarctica: Geochronology versus Biostratigraphy (A Progress Report). Bull. Polish Acad. Sci., Earth Sci,, 36(2): 133-145.

Birkenmajer K. \& Zastawniak E. 1986. Plant Remains of the Dufayel Island Group (Early Tertiary?), King George Island, South Shetland Islands (West Antarctic). Acta Paleobotânica, 26(1-2):33-54.

Birkenmajer K. \& Zastawniak E. 1989a. Late Cretaceous-Early Tertiary floras of King George Island, West Antarctic: their stratigraphic distribution and palaeoclimatic significance. In Origins and Evolution of the Antarctic Biota (ed. J.A. Crame). The Geol. Soc,, London, Spec. Pub., 47:227-240.

Birkenmajer K. \& Zastawniak E. 1989b. Late Cretaceous- Early Neogene Vegetation History of the Antarctic Peninsula Sector, Gondwana Break-up and Tertiary Glaciations. Bull. Polish Acad. Sci., Earth Sci., 37:63-88.

Birkenmajer K., Delitala M.C., Narebski W., Nicoletti M., Petrucciani C. 1986. Geochronology and migration of Cretaceous through Tertiary plutonic centers, South Shetland Islands (West Antarctica): subduction and hot spot magmatism. Bull. Polish Acad. Sci., Earth Sci., 34(3):243255 .

Bose M.N., Taylor E.L., Taylor T.N. 1990. Gondwana Floras of India and Antarctica. A survey and appraisal. $l n$ : T.N. Taylor \& E.L. Taylor (eds.) Antarctic Paleobiology. Springer Verlag, New York., pp. 118- 148 .

Brea M. 1998. Análisis de los anillos de crecimiento en leños fósiles de coníferas da la Formación La Meseta, Isla Seymour (Marambio), Antártida. Asociación Paleontológica Argentina, Publicación Especial (Paleógeno de América del Sur y de la Península Antártica), 5: 163 175.

Cantrill D. J. \& Nichols G.J. 1996. Taxonomy and paleoecology of Early Cretaceous (Late Albian) angiosperm leaves from Alexander Island, Antarctica. Review Paleob. Palymn., 92:1-28.

Cao Liu 1994. Late Cretaceous palynoflora in King George Island of Antarctica with references to its paleoclimatic significance. $I n$ : Stratigraphy and Paleontology of Fildes Peninsula, King George Island, Antarctica, Monograph 3, p. 76-90, pls. 1-4.

Case J. A. 1988. Paleogene Floras from Seymour Island, Antarctic
Peninsula. In: Feldmann, R., Woodburne, M.O. Geology and Paleontology of Seymour Island, Antarctic Peninsula. GSA Memoir; 169:489-498.

Case J. A., Woodburne M.O., Chaney D.S. 1988. A new genus of polydolopid marsupial from Antarctica. In: Feldmann, R., Woodburne, M.O. Geology and Paleontology of Seymour Island, Antarctic Peninsula. GSA Memoir; 169:489- 498.

Césari S., Parica C., Remesal M., Salani F. 1999. Paleoflora del Cretácico Inferior de la peninsula Byers, islas Shetland del Sur, Antártida. Ameghiniana, 36(1):3-22.

Crame J.A. 1992. Late Cretaceous palaeoenvironments and biotas: An Antarctic Perspective. Antarctic Science, 4:371- 382.

Crame J.A, Pirrie D., Riding J.B., Thomson M.R.A. 1991. CampanianMaastrichtian (Cretaceous) stratigraphy of the James Ross Island area, Antarctica. J. Geol. Soc. London, 148:1125-1140.

Cunningham W. D., Dalziel I. W. D., Lee Tung-Yi, Lawver L. A 1995. Southernmost South America-Antarctic Peninsula relative plate motions since $84 \mathrm{Ma}$ : Implications for the tectonic evolution of the Scotia Arc region. J. Geoph. Res., 100(B5):8257-8266.

Czajkowski S. \& Rösler O. 1986. Plantas fósseis da Península Fildes, Ilha King George (Shetland do Sul) - Morfografia das impressões foliares. Anais Acad. Bras. Cienc., 58(suplemento):99-100.

del Valle R.A. \& Rinaldi C.A. 1993. Structural features of the northeastern sector of the Antarctic Peninsula. In: Jornadas de Comunicaciones sobre Investigaciones Antárticas, Instituto Antártico Argentino, 2, Resumos, p. 261-267.

del Valle R.A., Elliot D.H., MacDonald D.I.M. 1992. Sedimentary basins on the east flank of the Antarctic Peninsula: proposed nomenclature. Antarctic Science, 4(4):477-478.

del Valle R.A., Lirio J.M., Lusky J.C., Morelli J.R., Nuñez H.J. 1997. Short note about Jurassic trees at Jason Peninsula. Antarctic Science, 9 (4): $443-444$.

Dettmann M. E. \& Jarzen D.M. 1990. The Antarctic/Australian rift valley: Late Cretaceous cradle of northeastern Australian relicts? Revi. Paleob. Palymn., 65:131- 144.

Dettmann M.E., Pocknall D.T., Romero E.J., Zamaloa M.C. 1990. Nothofagidites Erdtman ex Potonié, 1960; a catalogue of species with notes on the paleogeographic distribution of Nothofagus BI. (Southern Beech). Paleontological Bulletin of the New Zealand Geological Survey, 60: 1-79.

Doyle P. \& Whitham A.G. 1991. Palaeoenvironments of the Nordenskjöld Formation: an Antarctic Late-Jurassic-Early Cretaceous black shale-tuff sequence. In: R.V. Tyson \& T.H Pearson (eds.) Modern and Ancient Continental Shelf Anoxia. Geol. Soc. London, special Publ., 58:397-414.

Duane, A. 1994. Preliminary palynological investigation of the Byers Group (Late Jurassic-Early Cretaceous), Livingston Island, Antarctic Peninsula. Rev. Paleobo. Palynol., 84:113-120.

Dutra T. L. 1989. Informações Preliminares sobre a tafoflora do Monte Zamek (Baía do Almirantado, Ilha Rei George (Illhas Shetland do Sul), Antártica. Série Científica del INACH, 39:31- 42.

Dutra T. L. 1997a. Composição e história da vegetação do Cretáceo e Terciário da ilha Rei George, Península Antártica. Tese de Doutorado, Universidade Federal do Rio Grande do Sul, 488p.

Dutra T.L., 1997b. Primitive leaves of Nothofagus (Nothofagaceae) in Antarctic Peninsula: an Upper Campanian record and a betulaceous more than fagaceous morphological character. $I n$ : Congr. Geológico Chileno, Antofagasta, Chile, 9, Actas, p. 24-29 
Dutra T.L. 2000a. Nothofagus no noroeste da Península Antártica. II. Paleoceno Superior- Eoceno inferior. Revista da Universidade de Guarulhos, Geociências 5 (X Reunião de Palinólogos e Paleobotânicos), Número Especial : 131 - 136.

Dutra T.L. 2000b - Nothofagus no noroeste da Península Antártica. I. Cretáceo Superior. Revista da Universidade de Guarulhos, Geociências 5 (X Reunião de Palinólogos e Paleobotânicos), Número Especial: $102-106$.

Dutra T.L. 2001. Paleoflora da ilha 25 de Mayo, Península Antártica: contribuição à paleogeografia, paleoclima e para a evolução de Nothofagus. Asoc. Paleontol. Argentina, Public. Especial, 8: 29-37.

Dutra T.L. \& Batten D. 2000. The Upper Cretaceous flora from King George Island, an update of information and the paleobiogeographic value. Cretaceous Research, 21(2-3):181-209

Dutra T. L., Leipnitz B., Faccini U. F., Lindenmayer Z. 1996. A non marine Upper Cretaceous interval in West Antártica (King George Island, Northern Antarctic Peninsula). SAMC (South American Mesozoic Correlations-IGUS-381 Project) News, 5: 21-22.

Elliot D., 1988. The James Ross Basin, northern Antartic Peninsula. V Congr. Geológico Chileno, Comunicaciones, 39:226.

Farquharson G.W. 1984. Late-Mesozoic non-marine conglomeratic sequences of northern Antarctic Peninsula (The Botany Bay Group). British Antarctic Survey Bulletin, 65:1-33.

Frenguelli J. 1941 Nuevos elementos florísticos del Magellaniano de Patagonia Austral. Notas del Museo de La Plata, 6(30):173-202.

Gandolfo M.A., Marenssi S., Santillana S., 1998. Flora y paleoclima de la Formación La Meseta (Eoceno Médio), Isla Marambio (Seymour), Antártida. Asoc. Paleontológica Argentina, Publicacion Especial., 5:155-162.

Gazdzicka E. \& Gazdzicki A. 1994. Recycled Upper Cretaceous calcareous nannoplankton from the Pecten Conglomerate of Cockburn Island, Antarctic Peninsula. Polish Polar Res., 15(12):3-13

Gee C.T. 1989. Revision of the late Jurassic/Early Cretaceous flora from Hope Bay, Antarctica. Paleontographica, B213:149-214.

Hammer W.R. 1990. Triassic terrestrial vertebrate faunas of Antarctica. In: T.N. Taylor and E.L.Taylor (eds.) Antarctic Paleobiology and its role in the reconstruction of Gondwana. Springer Verlag, New York. pp. 42-50.

Hathway B. 2000. Continental rift to back-arc basin: JurassicCretaceous stratigraphical and structural evolution of the Larsen basin, Antarctic Peninsula. J. Geol. Soc. London, 157:417-432.

Hawkes D.D. 1961.The Geology of the South Shetland Islands. I. The petrology of the King George Island. Science Reptorts Falkdland Island Departament Survey, 26:1-28.

Johnson A.C. 1997. Cenozoic tectonic evolution of the Marguerite Bay area, Antarctic Peninsula, interpreted from geophysical data. Antarctic Science, 9(3):268-280

Kelm U. \& Hervé F. 1994. Ilite crystallinity of metapelites from the Trinity Peninsula Group, Lesser Antarctica: some implications from provenance and metamorphism. Inst. Antártico Chileno, Série Científica, 44:9-16.

Lawver L.A., Royer J.Y., Sandwell D.T., Scotese C.R. 1991. Evolution of the Antarctic continental margins. In: M.R.A. Thomson, J.A. Crame, J.W. Thomson (eds.) Geological Evolution of Antarctic. Cambridge University Press, pp. 533- 540.

Li Jianjun, Zhen Shuonan, 1994. New materials of bird ichnites from
Fildes Peninsula, King Goerge Island, Antarctica. In: Shen Yanbin (ed.) Stratigraphy and palaeontology of Fildes Peninsula, King George Island, Antarctica, Monograph 3, pp. 246-258.

MacDonald D.I.M., Barker P.F., Garrett S.W. Ineson J.R., Pirrie D., Storey B.C., Whitham A.G., Kinghorn, R.R.F, Marshall J.E.A. 1988. A preliminary assessment of the hydrocarbon potencial of the Larsen Basin, Antarctica. Marine and Petroleum Geology, 5:34-53.

Macellari C.E. 1988. Stratigraphy, sedimentology and paleoecology of Late Cretaceous/Paleocene shelf-deltaic sediments of Seymour Island. In: R.M. Feldmann \& M.O. Woodburne (eds.) Geology and Paleontology of Seymour Island. GSA Memoir, 169:25-53.

Marenssi S.A., Santillana S.N., Rinaldi C.A. 1998. Stratigraphy of the La Meseta Formation (Eocene), Marambio (Seymour) Island, Antarctica. Asociación Paleontológica Argentina, Publicacion Special, 5:137-146.

McLoughlin S., Lindström S., Drinnan A. 1997. Gondwanan floristic and sedimentological trends during the Permian-Triassic transition: new evidence from the Amery group, northern Prince Charles Mountains, East Antarctica. Antarctic Science, 9(3):281-298.

Millar I.L., Milne A.J., Whitham A.G. 1990. Implications of Sm-Nd garnet ages for the stratigraphy of northern Graham Land, Antarctic Peninsula. Zentralb. Geol. Paleontol., 1(1-2):97-104.

Millay M.A. \& Taylor T.N. 1990. New fern stems from the Triassic of Antarctica. Rev. Palaeobot. Palyn., 62:41-64.

Morel E., Artabe A.E., Ganuza D.G., Brea M. (1994) Las plantas fósiles de la Formación Monte Flora, en Bahia Botanica, Península Antártica, Argentina. I. Dipteridaceae. Ameghiniana, 31(1):23-31.

Murphy M.G. \& Kennett, J. P. 1985. Development of latitudinal thermal gradients during the Oligocene: oxygen isotope evidence from the southwest Pacific. In: J.P.Kennett, C.C. von der Borch et alli (eds) Initial reports of the Deep Sea Drilling Project, 90, p. 1347-1360.

Nathorst A.G. 1907. On the Upper Jurassic flora of Hope Bay,. Graham Land. Comptes rendues. 10 th. Intern. Geolo.Congr: (Mexico 1906), 10(2):1269-1270.

Olivero E. B. 1995. Molluscan Cretaceous biostratigraphy of the James Ross Basin (Antarctica) and the Austral Basin of Terra del Fuego (Argentina). SAMC News, 4: 5.

Olivero E.B., Scasso R.A., Rinaldi R.A. 1986. Revision of the Marambio Group, James Ross Island, Antarctica. Contribución del Instituto Antártico Argentino, 331:1-28.

Olivero E.B., Gasparini Z., Rinaldi C.A., Scasso R. 1991. First Record od Dinosaurs in Antarctica (Upper Cretaceous, James Ross Island): palaeogeographical implications. In: M.R.A. Thomson, J.A. Crame, J.W. Thomson (Eds.) Geological Evolution of Antarctic, Cambridge University Press, pp. 617- 622.

Orlando H. A., 1964. The Fossil Flora of the sorroundings of Ardley Peninsula (Ardley Island), 25 de Mayo Island (King George Island), South Shetland Islands. In: R.J.Adie (ed), Antarctic Geology, pp. 629-636.

Palamarczuk S., Ambrosini G., Villar H., Medina F., Martínez Macchiavello J.C., Rinaldi C. 1984. Las Formaciones Lopez de Bertodano y Sobral en la Isla Vicecomodoro Marambio, Antartida. In: XI Congr. Geol. Argentino, 11, Actas., 1:399- 419.

Pankhurst R.J. 1982. Sr-isotope and trace element geochemistry of Cenozoic Volcanic Rocks from the Scotia Arc and the Northern Antarctic Peninsula. In: C. Craddock, Antarctic Geosc., pp.229-234.

Philippe M., Barale G., Torres T., Covacevich V. 1993. First study of in situ fossil woods from the Upper Cretaceous of Livington Island, South Shetland Islands, Antarctica: palaeoecological investigations. 
Compte Rendu de l'Academie des Sciences, 317(2):103-108.

Philippe M., Torres T., Barale G., Thovenard F.1995. President Head, Snow Island, South Shetland Island, a key-point for Antarctic Mesozoic Paleobotany. Compte Rendus de la Academie des Sciences, 32(11):1055-106.

Pirrie D., Whitham A.G., Ineson J.R. 1991. The role of tectonics and eustasy in the evolution of a marginal basin: Cretaceous-Tertiary Larsen basin, Antarctica. IAS Special Publishing, 12:293-305.

Playford G. 1990. Proterozoic and Paleozoic palynology of Antarctica: a review. In: T.N.Taylor \& E.L. Taylor (eds.) Antartic Paleobiology, its role in the reconstruction of Gondwana, Springer-Verlag, pp. 51-70.

Pole M. 1992. Cretaceous macroflora of eastern Otago, New Zealand: Angiosperms. Austral. J. Botany, 40:169-206.

Pole M. 1994. An Eocene macroflora from the Taratu Formation at Livingstone, North Otago, New Zealand. Austral. J. Botany, 42:341-367.

Rees P. McA. 1993. Dipterid ferns from the Mesozoic of Antarctica, New Zealand and their stratigraphical significance. Paleontology, 36 (3):637-656.

Reguero M.A., Vizcaíno S.F., Goin F.J., Marenssi S.A., Santillana S.N. 1998. Eocene high-latitude terrestrial vertebrates from Antarctica as biogeographic evidence. Asociassión Paleontológica Argentina. Publicación Especial, 5:185- 198.

Richter M. \& Ward D.J. 1990. Fish remains from the Santa marta Formation (Late Cretaceous) of James Ross Island, Antarctica. Antarctic Science, 2(1):67-76

Riley T.R., Crame J.A., Thomson M.R.A., Cantrill D.J. 1997. Late Jurassic (Kimmeridgian - Tithonian) macrofossil assemblage from Jason Peninsula, Graham Land: evidence for a significant northward extension of the Latady Formation. Antarctic Science, 9(4):434-442.

Robert C. \& Kennett J. P. 1994. Antarctic subtropical humid episode at the Paleocene-Eocene boundary: clay-mineral evidence. Geology, 22 (3):211-214.

Romero F.J. 1978. Paleoecologia y paleofitogeografia de las tafofloras del Cenofítico de Argentina y areas vecinas. Ameghiniana, 15(1-2): 209-227.

Sadler P.M. 1988. Geometry and stratification of uppermost Cretaceous and Paleogene units on Seymour Island, northern Antarctic Peninsula. In: Feldmann, R.M. And Woodburne, M.O. (eds.) Geology and Paleontology of Seymour Islands, Antarctic Peninsula. GSA Memoir, 169:303-320.

Shen Yanbin. 1994. Subdivision and correlation of Cretaceous to Paleogene volcano-sedimentary sequence from Fildes Peninsula, King George Island, Antarctica. In: Shen Yanbin (ed.) Stratigraphy and Palaeontology of Fildes Peninsula, King George Island, Antarctica Monograph (China), 3: pp. 1-36.

Smellie J.L., Pankhurst R.J., Thomson M.R.A., Davies R.E.S. 1984. The geology of the South Shetland Islands: VI. Stratigraphy, geochemistry and evolution. British Antarctic Survey, Scientific Reports, 87:1-85.

Soliani JR. E.; Kawashita K.; Fensterseifer H. C.; Hansen M. A. F., Troian F. L. 1988. K-Ar Ages of the Winkel Point Formation (Fildes Peninsula Group) and associated intrusions, King George Island, South Shetland Islands, Antarctica. Instit. Antártico Chileno, Série Cientifica, 38:133-139.

Specht R.L., Dettmann M.E., Jarzen D.M. 1992. Community associations and structure in the Late Cretaceous vegetation of southeast Australasia and Antarctica. Paleogeo. Paleoctim. Paleoeco., 94: 283-309.

Tambussi C. P., Noriega J. I., Gazdzicki A., Tatur A., Reguero M. A., Vizcaino S. F. 1994. Ratite bird from the Paleogene La Meseta
Formation, Seymour Island, Antarctica. Polish Polar Reasearch, 15 $(1-2): 15-20$.

Tarling D.H. 1988. Gondwanaland and the evolution of the Indian Ocean. In: M.G. Audrey-Charles and A. Hallam (eds.), Gondwana and Tethys, GSA Special Publication, 37:61-77.

Taylor T.N. \& Taylor E.L. 1988. Late Triassic flora from the Mount falla, Queen Alexandra Range. Antarctic J. United States, 23(5):2-3.

Taylor T.N. \& Taylor F.L. 1990. Antartic Paleobiology, its role in the reconstruction of Gondwana, Springer- Verlag, N.Y. pp. 350.

Taylor E., Taylor T., Cúneo N. R. 1992. The Present is not the key to the past: A polar forest from the Permian of Antarctica. Science, 257: 1675-1677.

Torres G., T. 1990. Etude paleobotanique du tertiare de les Isles Roi George et Seymour, Antarctique. These de Doctorat. Laboratoire de Paléobotanique et Evolution de Végétaux de L'Université Claude Bernard LYON. 290 pgs. 40 pl. 2 tomes.

Torres G., T., Philippe M., Galleguillos H., Hauch F. 1995. New discoveries of plant fossils in Snow Island. Boletín Antartico Chileno, 14(1):25-28.

Troncoso A. 1986. Nuevas órgano-especies en la Tafoflora Terciaria Inferior de Península Fildes, Isla Rey Jorge, Antártica. Serie Científica del INACH, 34: 23-46.

Truswell E. M. 1990. Cretaceous and Tertiary Vegetation of Antarctica: A palynological perspective. In: T.N. Taylor. and E.L.Taylor (eds.) Antartic Paleobiology, its role in the reconstruction of Gondwana, Springer-Verlag, pp. 71-88.

Truswell E.M. 1991. Data report: palynology of sediments from Leg 119 drill sites in Prydz Bay, East Antarctica. In: E.K. Mazzullo \& N.J. Stewart (eds.) Proceedings of the Ocean Drilling Program, Scientific Results, 119, p. 941-945.

Wang, Y.X., Shen Yanbin. 1994. Rb-Sr isotopic dating and trace element, REE geochemistry of Late Cretaceous volcanic rocks from King George Island, Antarctica. In Stratigraphy and palaeontology of Fildes Peninsula, King George Island, Antartica (ed. Shen, Y.B.) Monograph 3, pp.109-131.

Wrenn J.H. \& Hart G.F. 1988. Paleogene dinoflagellate cyst biostratigraphy of Seymour Island, Antarctica. In: R.M. Feldmann \& M.O. Woodburne (eds.) Geology and Paleontology of Seymour Island. GSA Memoir; 169:321-447.

Zamaloa M.C., Romero J.E., Stinco L. 1987. Polen y esporas fósiles de la Formación La Meseta (Eoceno Superior-Oligoceno) de la Isla Marambio (Seymour), Antartica. In: VII Simpósio Argentino de Paleobotânica e Palinologia (Buenos Aires, 1987), 7, Actas, p. 199. 203.

Zastawniak E. 1981. Tertiary leaf flora from the Point Hennequin Group of King George Island (South Shetland Island, Antarctica). Preliminary Report. Studia Geologica Polonica, 72:97-108.

Zastawniak E. 1994. Upper Cretaceous leaf flora from the Blaszyk moraine (Zamek Formation), King George Island, South Shetland Islands, West Antarctica. Acta Paleobotanica, 34:119-163.

Zhou Zhiyan \& Li Haomin. 1994. Some Late Cretaceous plants from King George Island, Antarctica. In: Shen Yanbin (ed.) Stratigraphy and Paleontology of Fildes Peninsula, King George Island, Antarctica,Monograph (China), 3, p. 91- 105, pls. 1-3.

Manuscrito A-1444

Recebido em 30 de junho de 2003

Revisão da autora em 20 de maio de 2004 Revisão aceita em 30 de maio de 2004 